\title{
Analysis on the Education Inequality in China
}

\author{
*Shanghai Pinghe Bilingual School, Shanghai, 200135, China \\ "Huaer zizhu academy, Shanghai, 201100, China \\ *Corresponding author. Email: evaaaazyw@qq.com
}

Zhang Yiwen*, Liang Boran ${ }^{\#}$

\begin{abstract}
This article studies the past papers regarding education inequality published in two decades and highlights the data resources, research methods, and essential conclusions. Education inequality in this context refers to the uneven distribution of education resources such as school funding, experienced teachers, and education technology. After reviewing 15 published pieces of literature, we noticed that in recent years, the nature of education inequality in China has shifted from gender to geographics (differences in coastal/inland regions) and eventually to urban-rural inequality. We investigated the most recent data on urban-rural education inequality to analyze - based on a timeline, the phenomenons occurring in the Chinese education systems. From such analysis, we would then provide our policy recommendations. At last, we give our policy recommendations regarding China's formation mechanisms, arguing for regional teaching systems, increasing government spending on education, and an assessment system for urban and rural teaching quality.
\end{abstract}

Keywords: Education inequality, China, Urban-rural

\section{INTRODUCTION}

The beginning of modern higher education in China was marked by the establishment of Beiyang University in 1895 and the establishment of Beijing Normal University in 1898. In the past, China's education foundation was weak during the Republic of China (1912-1949) due to social unrest and the Japanese invasion. From the first year of the Republic of China to the end of the Second Sino-Japanese War, only 186,000 people took part in higher education. Although China modernized its education system a hundred years later than first world western countries, it successfully caught up very quickly. In 1986, a nine-year compulsory education was written into the newly promulgated Law on Compulsory Education. The system would be fully realized in 2011, eliminating illiteracy among the young and middle-aged population alike.

To achieve this extraordinary feat, the Chinese government took many innovative measures. In 1999, government policies encouraged higher education institutes to accept more students, and by 2000 , a total of 12 million people were studying in universities - and over the next two decades, this number would be more than tripled to 41.83 million (in 2020). The top institutesTsinghua University and Peking University-now rank 17th and 18th globally in the 2022 QS rankings, along with nine other Chinese universities placing in the top 100 .

However, the lightspeed development of higher education does not come with a solidified system - the underlying inequality problems being the focus of this article. We attempt to answer the questions: What are the current situations of Chinese education inequality? What are the factors that lead to the development process of the main problems of inequality? What policies should the government adopt in order to promote uniform education? By the end of this paper, we hope to thoroughly demonstrate the reality of education in China and the advantages of policies that should be adopted to improve the status quo.

\section{LITERATURE REVIEW}

\subsection{China Context}

In 2005, Qian and Smyth [1] used Gini coefficients and decomposition analysis to measure educational inequality in terms of outputs of education (educational attainment) rather than inputs to education (expenditure on education). Two indicators for educational attainment, the average years of schooling (AYS) in 30 provinces in China and the percentage of graduates of junior 
secondary schools entering senior secondary schools (PG) for each province separately in rural and urban areas, improved and Gini coefficients of education declined from 1990 to 2000. Decomposition of Gini coefficients indicates the gap in education between the coastal and inland provinces reflects a faster decline in educational inequality within the coastal provinces than within the inland provinces.

In 2006, Hannum and Wang [2] used dissimilarity index with 2000 census data on year and location of birth and educational attainment, in order to prove the link between the birth province and access to primary school has dramatically increased across 5 -year birth cohorts, as the few without access to primary school are even more concentrated in impoverished areas.

In 2007, Sun and Qi [3] used the data of two censuses in 1990 and 2000 to calculate the average years of school attainment and the Gini coefficient of school attainment. Also, they took regression analysis to discuss the influence of the development of ethnic education on educational equality. The results showed that each nationality's average years of school attainment were increased with an average extent of 2.27 years. Nevertheless, the level was enlarged among nationalities, indicating that sufficient attention in solving educational inequality within each nationality was still imperative for policy-makers.

In 2014, Yang, Huang, Liu [4] used the decrease of the Gini coefficient to indicate that education expansion policy in the last decades had contributed to a sharp decline in education inequality and an improvement of average years of schooling (AYS). However, the Shapley decomposition based on regression analysis showed that the most urban-rural division contributed to education inequality, decreasing significance by social stratification division, age, gender disparity, and regional gaps.

In 2015, Zhang, Li, Xue [5] used CFPS and RUMiC survey data to examine the education performance of migrants' children and compared this to the education performance of their rural and urban counterparts. The results showed the education performance of rural-tourban children was significantly worse than that that urban residents' children.

In 2016, Tang [6] used CGSS2008 data and logistic regression model to identify that socioeconomic status and cultural background had a more significant effect on primary education than higher education, especially in low social class.

\subsection{Lack of timeliness}

In 1999, Hannum [7] summarized previous findings and identified implications for research priorities in and beyond China. It mainly focuses on shifts in the political context of education policy and the implications of these shifts for urban and rural areas, as well as trends in urbanrural educational inequality observed along with a variety of indicators, including enrollment at primary and secondary levels; several full-time teachers at the primary, junior high, and academic senior high levels in urban and rural China; cross-cohort changes in the rate of attainment of primary education and the transition to junior high school by residence status and gender.

In 2009, Cheng [8] explained three kinds of educational inequality in primary education in China. Urban-rural inequality exists in school enrollment and achievement and educational financing; Regional inequality resides between coastal and inland regions and provinces. Gender inequality exists in educational attainment and achievement, especially at the secondary school level.

Similarly, this paper analyzes the trend and focus of education inequality in China in the past decade, aiming to be more time-sensitive and update China's most recent education development.

\section{THE EXTENT OF CHINA'S EDUCATION INEQUALITY}

\subsection{Gender inequality}

In 2009, Hannum, Kong, and Zhang [9] illustrated the following phenomenons: Firstly, families think that daughters are less capable or less worthy of investment. Secondly, families expect that sons' returns to education will be better than daughters' in the labor market. Thirdly, families expect future support from sons more than from daughters; Parents invest less in the education of girls than boys. Fourthly, girls have more unsatisfactory educational performance than boys do. Finally, girls have poorer attainment outcomes than boys do.

In 2014, Dong, Li, Yang [10] did qualitative studies on male and female education in ten villages from five western provinces in China. The results show high school attendance and retention rates among boys but high withdrawal rates from school among girls. Among adults, the illiteracy rate is much higher in women than in men, and men's average number of years of education is much greater than women's, indicating apparent gender inequality in rural education. They survey families in five provinces as cases and figure out the reasons behind the significant gender inequality. First, parents have higher expectations for boys' education than for girls, so girls have to sacrifice their schooling time at early ages in order to help their families build resources for livelihoods, while boys only participate in seasonal agricultural activities. Also, poverty is also an significant factor for education inequality. When a family's natural, physical, and, in particular, financial capital is extremely limited, girls' access to education is often sacrificed, thus aggravating gender inequalities in education. In addition, 
schools are generally located in remote areas due to the shortage of educational resources in poor rural regions, leading to the safety issue, especially for girls.

\subsection{Regional inequality}

\subsubsection{Coastal-inland inequality}

In the world, the economies of seaside countries or regions are generally ahead of the inland ones since being along the coast allows them to access the vast world overseas, trade internationally efficiently, and have cultural exchanges. Therefore, the economies of these coastal areas develop naturally in this process; their cultures are also constantly assimilating and mutually exchanging. Eventually, the coastal areas come ahead of the inland areas because the former can directly contact the rest of the world.

The coastal areas can be broadly defined as regions with a coastline- Beijing, Shanghai, Jiangsu, Guangzhou,
Shenzhen, Tianjin, et cetera. On the other hand, the inland regions are defined as more than 500 kilometers away from the coastline - for example, Urumqi, Chengdu, Xi'an, Hohhot, et cetera.

The issue of education equity in different regions is mainly reflected in the inequity between the east and the west. The east and the middle west have experienced different degrees of national support in the development of our country due to their specific geographical position and historical reasons, which are also revealed in the education field. Further studies find out that the imbalance of economic development also causes this.

According to a survey, illiteracy in China is less than $4 \%$ in most eastern provinces. However, the rate is more than $10 \%$ in some western areas, including Tibet, which has more than $30 \%$. The ratio of people who have an education past the middle school in our country is about $50 \%$ on average, of which about $60 \%$ are in the southeast coastal provinces, only about $28 \%$ in provinces such as Yunnan and Guizhou, and even lower, $10.8 \%$ in Tibet.

Table 1. The average number of years of schooling for the population aged 15 and above in each region time:2020 data sources(National Bureau of statistics of the People's Republic of China).

\begin{tabular}{c|c}
\hline Region & Year \\
\hline China & 9.91 \\
\hline Beijing & 12.64 \\
\hline Tianjin & 11.29 \\
\hline Shanghai & 11.81 \\
\hline Jiangsu & 10.21 \\
\hline Shanxi & 10.45 \\
\hline Inner Mongolia & 10.8 \\
\hline Tibet & 6.75 \\
\hline Qinghai & 8.85 \\
\hline
\end{tabular}

\subsubsection{Urban-rural inequality}

In 2015, Zhang, Li, Xue [5] showed that the education performance of rural-to-urban children was significantly worse than that of urban residents' children. The urbanrural disparity is mainly because of the dualization of urban and rural structures in China and the uneven allocation of state monetary funds.

\subsubsection{Dualization of urban and rural structure in China}

In the early years after the founding of the People's Republic of China, the Chinese government paid too much attention to industry development in cities and neglected the development of agriculture in the suburbs. In this case, agricultural products, the primary sources of rural residents' income, do not have high added value, so the disposable income is lower than that of urban residents. The meager income leads to a low enrollment rate and a high dropout rate of rural students since a family's income is the material basis of education.

In addition, rural areas do not have as comprehensive a social security system as urban areas. Urban schools usually have indoor gymnasiums, more formal stadiums, swimming pools, basketball courts, and other venues, while rural schools rarely have these advanced education facilities. Moreover, the rural school buildings accounted for $86 \%$ of China's nearly 20 million square meters of dangerous school buildings, which is major hidden trouble for the education safety of rural students. 
Therefore, teachers across the country will prioritize urban schools with better conditions when choosing jobs. Thus rural schools have to reduce the requirements for the recruitment of teachers, resulting in the low overall quality of teachers in rural education.

Finally, the household registration system in China makes a difference in the access of urban and rural students. According to regulations under the system, students can only study where they registered their residence, which makes the educational resources available to urban and rural students not consistent; to be specific, rural students can only study in the countryside. Although some private schools are willing to accept rural students, the fees are too high for ordinary rural families.

\section{POLICY RECOMMENDATION}

\subsection{Establish a regional teaching system, share resources as much as possible}

The sharing mechanism of teaching facilities within the region should be established. Due to the massive difference between rural and urban teaching facilities, the lack of relevant teaching facilities can be solved only through the cooperation between each school district in the region. For example, students from all schools within the region can share an indoor gymnasium on a regional campus by issuing relevant passes. Plus, a teaching exchange platform for teachers in the region should be established so that rural teachers can obtain many urban teachers' teaching ideas and the latest teaching methods; through mutual communication, rural teachers can further improve their teaching work.

\subsection{Increase spending on education}

It must be admitted that the shortage of educational funds is the most fundamental reason for the problems of inequality in China's urban and rural education. Firstly, the government should increase the investment in the repair of rural school buildings in danger to ensure the safety of rural students and provide them with a good learning environment. What is more, the government should try to balance the salary and treatment of urban and rural teachers since a qualified and equal material basis for rural schools to recruit teachers is imperative, ensuring more excellent teachers will be willing to join the rural teacher team. Also, the government should pay more attention to the special students in rural areas. Due to the inadequate economic income of rural residents, there is a higher proportion of poor students than in urban areas. In addition, the government should pay attention to the left-behind students materially and spiritually to be more likely to learn even without their parent's supervision.

\subsection{Establish an assessment system for urban and rural teaching quality}

Governments at all levels and education departments can work out a sound evaluation system for teaching quality. On the one hand, it can promote the improvement of urban and rural teaching quality; on the other hand, it can find the reasons for the gap between urban and rural teaching quality and then put forward solutions. The evaluation system should be composed of various quantitative indicators. Different quantitative indicators should be formulated according to the different conditions of each region for regular or irregular assessment. For example, the government can use the system to allocate funds between higher education and primary education to allocate fiscal expenditures properly.

\section{CONCLUSION}

This essay aimed to use empirical evidence and data from three different perspectives to analyze the primary underlying causes of education inequality and thus to recognize possible methods of alleviating the problem. Education inequality has manifested itself as a significant social and economic problem over the time of accelerated yet unsolidified development of higher education in China and should be placed on a very high priority similar to that of urbanization. In the current context, we identify the policies mentioned in section 4 as realistic and helpful as a countermeasure to education inequality. Achieving uniform education takes time, effort, and resources, and we hope to be part of the drive that completes equality in the not-so-distant future.

\section{REFERENCES}

[1] XiaoLei Qian and Russell Smyth. Measuring Regional Inequality of Education in China: Widening Coast-Inland Gap or Widening RuralUrban Gap?, J. Int. Dev. 2005(20): 132-144.

[2] Emily Hannum, Meiyan Wang. Geography and educational inequality in China, China Economic Review 17, 2006: 253-265.

[3] Sun Baicai, Qi Jinyu. Development of ethnic education and educational equality in China, Front. Educ. China, 2007, 2(4): 528-535.

[4] Jun Yang, Xiao Huang, Xin Liu. An analysis of education inequality in China, International Journal of Educational Development, 2014(37): 2-10.

[5] Dandan Zhang, Xin Li, Jinjin Xue. Education Inequality between Rural and Urban Areas of the People's Republic of China. Migrants' Children Education, and Some Implications, Asian Development Review, 2015, 32(1): 196-224. 
[6] Junchao Tang. Lost at the starting line: a reconsideration of educational inequality in China, 1978-2008, The Journal of Chinese Sociology, 2016(3): 8.

[7] Emily Hannum. Political Change and the Urban-Rural Gap in Basic Education in China, 1949-1990, Comparative Education Review, 1999, 43(2): 193211.

[8] Henan Cheng. Inequality in Basic Education in China: A Comprehensive Review, International Journal of Educational Policies. 2009, 3(2): 81-106.
[9] Emily Hannum, Peggy Kong, Yuping Zhang. Family sources of educational gender inequality in rural China: A critical assessment, International Journal of Educational, Development 29, 2009, 474-486.

[10] Dong Qiang, Li Xiaoyun, Hongping, Zhang Keyun. Gender Inequality in Rural Education and Poverty, Chinese Sociology \& Anthropology, 2014(40):4+64-78. 